Article

\title{
The Refugee Game: The Relationship between Individual Security Expenditures and Collective Security
}

\author{
João Ricardo Faria ${ }^{1}$, Andreas Novak ${ }^{2}$, Aniruddha Bagchi ${ }^{3}$ (D) and Timothy Mathews ${ }^{3, *(D)}$ \\ 1 Department of Economics, Florida Atlantic University, Boca Raton, FL 33431, USA; jfaria@fau.edu \\ 2 Department of Business Decisions and Analytics, University of Vienna, Vienna 1090, Austria; \\ andreas.novak@univie.ac.at \\ 3 Department of Economics, Finance, and Quantitative Analysis, Kennesaw State University, \\ Kennesaw, GA 30144, USA; abagchi@kennesaw.edu \\ * Correspondence: tmathew7@kennesaw.edu; Tel.: +1-470-578-2072
}

Received: 22 April 2020; Accepted: 18 May 2020; Published: 4 June 2020

\begin{abstract}
This paper studies a three player hierarchical differential game (with a large country, a small country, and a terrorist organization), to analyze the actual European refugee situation. Terrorists may enter Europe as refugees, taking advantage of the Open Door Policy, to attack both countries. There are two scenarios: myopia and full awareness. Countries are myopic when they ignore each other's security efforts, and the terrorist group only considers the weakest link's security efforts. A comparison between the scenarios shows that for an extremely impatient large country, full awareness yields a greater level of security effort for the large country, a greater level of security effort for the small country, and more terrorist attacks. This is, however, an unstable equilibrium. The full awareness model with a patient large country is stable and lies in between the previous model and the myopic model. Although it yields larger investments in security, this still results in more terrorist attacks than the myopic model. Continental safety is higher in the myopic model than in the full awareness model.
\end{abstract}

Keywords: differential game; terrorism; refugee crisis; externalities; international public goods

\section{Introduction}

In August 2015, German Chancellor Angela Merkel announced her new Open Door Policy (ODP) "to provide refuge to anyone coming from Syria in addition to others seeking protection from violence and warfare." ${ }^{11}$ A few months later, on November 13, 2015, Paris suffered terror attacks that killed at least 130 people and wounded hundreds. ${ }^{2}$ There is evidence that some of the Paris attackers traveled to Syria, ${ }^{3}$ raising concerns that ISIS was taking advantage of the ODP to infiltrate its operatives to organize, lead, and carry out terrorist attacks in Europe. In 2016, officials at Frontex, EU's border and coast guard agency, admitted that ISIS terrorists are taking advantage of disorganized border checks by posing as migrants to infiltrate Europe. ${ }^{4}$ Not surprisingly, as reported by the Pew Research Center, most Europeans fear ISIS terrorist attacks and think that refugees will increase the likelihood of

Der Spiegel, 21 Sept., 2015, http://www.spiegel.de/international/germany/refugee-policy-of-chancellor-merkel-divideseurope-a-1053603.html.

CNN, 30 Nov., 2015, http://www.cnn.com/2015/12/08/europe/2015-paris-terror-attacks-fast-facts.

BBC, 27 April, 2016, http://www.bbc.com/news/world-europe-34832512.

Sunday Express, April 6, 2016, http://www.express.co.uk/news/world/658508/EU-migrant-crisis-Islamic-State-ISIS-refugeesSyria-Greece-Italy-terror-Paris-attacks. 
terrorist attacks in their countries. Across ten European countries, in response to the statement "ISIS is a major threat to their country", the median level of agreement with the statement was $76 \%$ and in response to the statement "Refugees will increase the likelihood of terrorism in our country", the median level of agreement with the statement was 59\%.5

This paper puts forward a hierarchical differential game as a representation of the actual European refugee situation. In the model, there are three agents, two countries-one large, which is the leader, and one small-and one terrorist organization. Terrorists may enter Europe as refugees, taking advantage of the ODP, to attack both countries. It has been discussed in previous research (Hausken [1] (2002)) that the reliability of a system depends upon (i) its weakest link if it is organized as a series, and on (ii) its strongest link if it is organized as a parallel system. If the countries allow unrestricted movement of persons between them, infiltration of one country is as good as infiltration of both. Hence, in this context, the security of the continent (which is the 'system' in this case) depends upon its weakest link, which is what we assume in this paper. We analyze two possible scenarios. In the first scenario, both countries are myopic and ignore each other's security efforts, and the terrorist group is also myopic in that it only considers the weakest link's security effort, which is the small country. It follows from Hausken [2] (2006) that the security efforts of each country are interdependent and can force the terrorist group to optimally determine its target; this is known as the substitution effect. (Such substitution effects have also been identified and analyzed in static, incomplete information environments-see, for example, Bier, Oliveros, and Samuelson [3] (2007) and Mathews and Lowenberg [4] (2012)). Presently, this is considered in the second scenario, in which we assume that there is full awareness by all agents. Both countries take each other's security efforts into consideration, and the terrorist group also pays attention to the large country's security efforts. A comparison between the scenarios yields the result that for an extremely impatient large country, full awareness yields a greater level of security effort for the large country, a greater level of security effort for the small country, and, because of backlash (e.g., Faria and Arce [5,6] (2005, 2012a); Siqueira and Sandler, [7] (2007)), more terrorist attacks. Despite greater security efforts, terrorist attacks escalate. We show, however, that this equilibrium is unstable. The best scenario for the continental safety as a whole is the myopic scenario.

The paper is structured as follows. The next section presents a literature review. The differential game is specified in Section 3. Section 4 presents the stability analysis, and the comparison between the scenarios is presented in Section 5. Concluding remarks appear in Section 6.

\section{Literature Review}

Studies on the link between refugees and political violence are few and recent. It has been recognized that refugees are victims of violence, but they can also spread conflict and instability to their host countries. Lischer [8] (2005), Salehyan and Gleditsch [9] (2006) and Buhaug and Gleditsch [10] (2008) study the link between refugees and the spread of civil war. Salehyan [11] (2008) examines the negative externalities for receiving states associated with refugee flows, and shows how refugee flows between states significantly increase the likelihood of militarized interstate disputes. When rebel organizations find sanctuaries in neighboring countries, insurgencies give rise to disputes between states. Salehyan [12] (2009) studies the cases of the Nicaraguan and Rwandan civil wars, as well as Kurdish PKK and Taliban fighters in Pakistan.

The issue of terrorist organizations finding sanctuary in other countries was analyzed by Piazza [13] (2008) and Barros et al. [14,15] (2007, 2008). Piazza [13] (2008) finds that failed states are statistically more likely to hold terrorist groups that commit transnational attacks. The articles by Barros et al. analyze terrorist attacks targeting US citizens in Europe and Africa. Their main finding is that terrorist attacks are persistent. Barros et al. [15] (2008) presents a model that bridges the civil war literature

5 See: http://www.pewresearch.org/fact-tank/2016/12/06/4-factors-driving-anti-establishment-sentiment-in-europe/ft_1612-06_europeconcerns_security. 
(e.g., Murdoch and Sandler [16] (2004); Collier and Hoeffler [17] (2004)) with terrorist activities, where conflict-ridden countries become safe havens for terrorists. Related, but in some respects in the opposite direction, Lowenberg and Mathews [18] (2008) argue that a target country like the US may find it optimal to station forces near a terrorist's base of operations as an 'easy target' in order to divert attacks away from domestic targets within their homeland.

Only recently has the link between refugees and terrorism received proper scientific attention. Choi and Salehyan [19] (2013) examine a database of 154 countries from 1970 through 2007. They show that countries with high numbers of refugees are more likely to experience both domestic and international terrorism. A natural policy recommendation is that humanitarian efforts must be coupled with robust security provisions.

Analytically, terrorism has been modeled in dynamic settings by several authors using a plethora of frameworks—for surveys see e.g., Bueno de Mesquita [20] (2008) and Intriligator [21] (2010)—such as systems of differential and difference equations, optimal control, dynamic programming, and differential-difference equations, (e.g., Feichtinger et al. [22] (2001); Udwadia et al. [23] (2006); Caulkins et al. [24] (2008); Jensen [25] (2011); Faria and Arce [26] (2012b)). New approaches include integral equations (e.g., Faria [27] (2011)) and stochastic models such as queue theory and optimal stopping approaches (see Kaplan [28] (2010) and Jensen [29] (2016)).

The use of differential games as a tool to analyze terrorism is still in its infancy. Most of the models analyze a differential game between a government fighting a terrorist organization. Faria [30] (2003) generates terror cycles with the government as the Stackelberg leader. In Feichtinger and Novak [31] (2008), the differential game is simultaneous and both agents are subjected to the dynamics of terrorist resources, characterized by a non-linear growth function. In a related framework, Novak et al. [32] (2010) consider a state-separable differential game and determine Nash and Stackelberg solutions in an analytic form. They show that, for specific parameter values, the government acts more aggressively and terrorists more cautiously in the Stackelberg equilibrium compared to the Nash case. Other studies involving dynamic games include Behrens et al. [33] (2007), Wang et al. [34] (2016) Short et al. [35] (2017). For an updated general survey, see Gaibulloev and Sandler [36] (2019).

The contribution of the present paper is to provide a differential game model to study the link between refugees and terrorism considering externalities between countries with respect to provision of security.

\section{Differential Game}

Consider a game with three players: a terrorist group plus two countries, small and large. The ultimate differentiating factor between a large country and small country is the overall capacity to fight terrorists, with the large country being relatively more effective at implementing counterterror measures. This capacity is likely related to (and determined by) factors such as population, Gross Domestic Product, geographic size, and military spending. The terrorist group may use operatives under the pretense of refugees to more easily penetrate Europe, taking advantage of the Open Door Policy (ODP). While we will refer to Europe throughout the discussion, we do so not because we think the analysis is limited and applicable only to Europe, but rather because our motivating example (of terrorism in the context of refugees and the ODP) is European. When thinking about how the model and its results could be applied (either to Europe or elsewhere, such as Africa, Asia, or Latin America), we recognize that the two countries need not be contiguous, but should be closely related to each other in geographic, social, or political terms, plus have relatively easy movement of people between the two countries (which is clearly true within Europe).

The terrorist group aims at attacking both countries by exerting effort $A$. The large and the small countries act to guarantee their own security, with $L$ and $G$ respectively denoting chosen levels of security efforts. The large country is the Stackelberg leader in the game. The public safety, denoted $S$, of the continent depends positively on $G$ and $L$ and negatively on $A$. 
We present and analyze two scenarios. In the first scenario, all agents are myopic, both countries ignore each other's security measures, and the terrorist group attacks the weakest link, so it targets the small country's security. In the second scenario, all agents are aware of each other, both countries pay attention to each other's security measures, and the terrorist group pays attention equally to both countries.

\subsection{First Scenario: Myopia, Countries Ignore Each Other}

In this section, we consider the myopic model. Countries ignore that their expenditure on safety has a positive externality on the safety of their neighbors and on the whole continent. As followers in the differential game, the small country plays against the terrorist group. The small country's welfare is positively affected by its own security efforts, $G$, and is negatively affected by the terrorist's activities, $A$. The parameters $a_{1}, a_{2}$ represent for the small country the constant term of the marginal utility of $G$ and the marginal cost of a terrorist attack $\mathrm{A}$, respectively.

The terrorist's benefits increase in $A$ but decrease in $G$ and $S$, where $S$ is Europe's public safety. Terrorists are only paying attention to the security efforts of the small country because they see it as the weakest link (see Enders and Sandler [37] (2012), pp. 126-129). The parameters $b_{1}, b_{2}$ represent for the terrorist organization the constant term of marginal utility of an attack $\mathrm{A}$, and the marginal cost of the combination of anti-terror safety measures taken at the small country and Europe as a whole, SG, respectively. The specification SG captures the total impact of anti-terror safety measures at the micro (small country) and macro level (Europe) at the same time. (One could certainly consider the micro and macro safety measures separately; however, one of the objectives of this paper is to examine their interaction).

Each player maximizes the present value of its benefits net of costs, given by the following objective functions. The small country's objective function is

$$
\underset{G}{\operatorname{Max}} \int_{0}^{\infty}\left[a_{1}\left(G-0.5 G^{2}\right)-a_{2} A\right] e^{-\delta t} d t
$$

and the terrorist group's objective function is

$$
\operatorname{Max}_{A} \int_{0}^{\infty}\left[b_{1}\left(A-0.5 A^{2}\right)-b_{2} S G\right] e^{-r t} d t
$$

Recall, the strategy choice variable of the small country, denoted by $G$, is its level of security and the strategy choice variable of the terrorist group, denoted by $A$, is its effort level of attack.

Including $S$ and $G$ multiplicatively (as opposed to additively) in (2) allows for greater interaction between the variables in regards to their marginal impact on the objective function. Furthermore, these assumed functional forms, in which benefits are linear and costs are convex with respect to the choice variable, give rise to first-order conditions which are linear, so that closed form solutions can be easily determined. Note that $\delta$ and $r$ are respectively the rate of time preference of the small country and terrorist group. For the small country government, $\delta$ captures the trade-off between safety today and safety in the future. By the same token, the parameter $r$ captures the trade-off between attacks today and future attacks for the terrorist organization. Higher values of $\delta$ and $r$ denote impatience, i.e., the present is much more valued than the future.

While assuming specific functional forms is restrictive, by doing so, closed form solutions can be obtained. Moreover, the specific assumptions made throughout exhibit reasonable properties. For example, these two decision makers face convex adjustment costs associated with their own activity. Further, the terrorist group is negatively impacted by the combination of small country security efforts and the level of public safety in Europe, while the small country is negatively impacted by terrorist group activities. The intuition for the logistic functions representing benefits for both players is that for 
initial levels of $G$ and $A$, benefits grow very rapidly, however, after some level of $G$ and $A$, diminishing marginal utility kicks in and benefits grow slowly.

The state equation that describes the evolution over time of public safety in Europe, $S$, is given by,

$$
\dot{S}=\gamma L+\alpha G-\beta A-\sigma S-\Psi
$$

where $\dot{S}=\frac{d S}{d t}$, the initial value of $S(0)$ is given, and $L$ is the large country's security effort. Public safety grows over time with large and small countries' security efforts, $L$ and $G$, and is reduced by terrorist activity $A$, where parameters $\gamma, \alpha, \beta$, represent their marginal impacts on the time variation of Europe's safety, respectively. In addition, $\Psi$ is a positive constant and $\sigma$ is the marginal impact of $S$ on $d S / d t$. All parameters of the model are positive.

The small country's Hamiltonian is

$$
H_{G}=\left[a_{1}\left(G-0.5 G^{2}\right)-a_{2} A\right]+\lambda_{1}[\gamma L+\alpha G-\beta A-\sigma S-\Psi]
$$

and the terrorists' Hamiltonian is

$$
H_{A}=\left[b_{1}\left(A-0.5 A^{2}\right)-b_{2} S G\right]+\lambda_{2}[\gamma L+\alpha G-\beta A-\sigma S-\Psi]
$$

Maximizing the Hamiltonians with respect to the control variables yields,

$$
\frac{\partial H_{G}}{\partial G}=0 \Rightarrow a_{1}(1-G)+\lambda_{1} \alpha=0 \Rightarrow G=1+\frac{\alpha \lambda_{1}}{a_{1}}
$$

and

$$
\frac{\partial H_{A}}{\partial A}=0 \Rightarrow A=1-\frac{\beta \lambda_{2}}{b_{1}}
$$

The adjoint equations are,

$$
\dot{\lambda}_{1}-\delta \lambda_{1}=-\frac{\partial H_{G}}{\partial S} \Rightarrow \dot{\lambda}_{1}=(\delta+\sigma) \lambda_{1}
$$

and

$$
\dot{\lambda}_{2}-r \lambda_{2}=-\frac{\partial H_{A}}{\partial S} \Rightarrow \dot{\lambda}_{2}=(r+\sigma) \lambda_{2}+b_{2} G
$$

in which the usual transversality conditions apply. Differentiating (4) and (5) with respect to time and substituting them into (6) and (7) yields the dynamic reaction functions, the best dynamic reply functions of the small country and the terrorist organization,

$$
\dot{G}=(\delta+\sigma)(G-1)
$$

and

$$
\dot{A}=(r+\sigma)(A-1)-\frac{\beta b_{2}}{b_{1}} G
$$

As expected, (8) and (9) reflect how the small country and the terrorist organization affect each other. It is important to stress that these best response functions do not take into explicit account the role of the large country security effort, $L$.

The large country as the leader considers the dynamic reaction function of the small country and terrorists, i.e., Equations (8) and (9), as well as the state Equation (3), in maximizing the objective function,

$$
\underset{L}{\operatorname{Max}} \int_{0}^{\infty}\left[\xi\left(L-0.5 L^{2}\right)-\varphi A\right] e^{-R t} d t
$$


subject to (3), (8) and (9), where $R$ is the large country's rate of time preference. (It has already been noted that the equilibrium depending upon if the large country is "extremely impatient" or not—as will be fully explained with Section 5 , the degree of and cutoff level of impatience will be specified in terms of the parameters $r, \sigma$, and $R$ ). Recall the strategy choice variable of the large country, denoted by $L$, is its level of security. In the large country's objective function (10), there are convex (quadratic) adjustment costs associated with the level of its own security effort and a negative effect of terrorists' actions.

The current-value Hamiltonian of the large country problem is

$$
H_{L}=\left[\xi\left(L-0.5 L^{2}\right)-\varphi A\right]+\lambda_{L}[\gamma L+\alpha G-\beta A-\sigma S-\Psi]+\mu_{1}[(\delta+\sigma)(G-1)]+\mu_{2}\left[(r+\sigma)(A-1)-\frac{\beta b_{2} G}{b_{1}}\right]
$$

where $\lambda, \mu_{1}$, and $\mu_{2}$ are respectively the large country's shadow prices of public safety, the small country's action, and the terrorist's action. The first-order condition and adjoint equations are:

$$
\begin{gathered}
\frac{\partial H_{L}}{\partial L}=0 \Rightarrow \xi(1-L)+\lambda_{L} \gamma=0 \Rightarrow L=1+\frac{\lambda_{L} \gamma}{\xi} \\
\dot{\lambda}_{L}-R \lambda_{L}=-\frac{\partial H_{L}}{\partial S} \Rightarrow \dot{\lambda}_{L}=(R+\sigma) \lambda_{L} \\
\dot{\mu}_{1}-R \mu_{1}=-\frac{\partial H_{L}}{\partial G} \Rightarrow \dot{\mu}_{1}=R \mu_{1}-\left\{\alpha \lambda_{L}+\mu_{1}(\delta+\sigma)-\mu_{2} \frac{\beta b_{2}}{b_{1}}\right\}
\end{gathered}
$$

and

$$
\dot{\mu}_{2}-R \mu_{2}=-\frac{\partial H_{L}}{\partial A} \Rightarrow \dot{\mu}_{2}=R \mu_{2}-\left\{-\varphi-\beta \lambda_{L}+\mu_{2}(r+\sigma)\right\}
$$

From Equation (12), the steady state equilibrium value of the large country's shadow price of public safety, $\lambda_{L}$, is,

$$
\dot{\lambda}_{L}=0 \Rightarrow \lambda_{L}=0
$$

Note that, as a consequence of (13), we have from (11) that the steady state equilibrium value of the large country security, $\bar{L}$, is constant and unitary:

$$
\bar{L}=1
$$

It then follows from Equation (8) that the steady state value of the small country security $\bar{G}$ is also constant and unitary:

$$
\dot{G}=0 \Rightarrow \bar{G}=1
$$

Substituting the steady state value of $\bar{G}$ into Equation (9) yields the steady state value of the terrorist organization's actions:

$$
\dot{A}=0 \Rightarrow \bar{A}=1+\frac{\beta b_{2}}{b_{1}(r+\sigma)}
$$

Substituting (15), (14), and (16) into (3) yields the steady state value of public safety in Europe:

$$
\dot{S}=0 \Rightarrow \bar{S}=\sigma^{-1}\left[\gamma+\alpha-\beta\left(1+\frac{\beta b_{2}}{b_{1}(r+\sigma)}\right)-\Psi\right]
$$

\subsection{Second Scenario: Countries Consider Each Other}

Now, we consider a full awareness model. Countries know that their expenditure on safety have a positive externality on the safety of their neighbors and on the whole continent. Being myopic or fully aware in our model can be thought in terms of information-that is, of incomplete (myopic) versus complete (aware) information, see Hausken [38] (2014). 
The small country problem is:

$$
\underset{G}{\operatorname{Max}} \int_{0}^{\infty}\left[a_{1}\left(G-0.5 G^{2}\right)-a_{2} A+a_{3} L+a_{4} S\right] e^{-\delta t} d t
$$

Note that, in contrast to Equation (1), the objective function captures the positive impact of large country and continental safety measures.

The terrorist group problem is:

$$
\operatorname{Max}_{A} \int_{0}^{\infty}\left[b_{1}\left(A-0.5 A^{2}\right)-b_{2} S(G+L)\right] e^{-r t} d t
$$

In contrast with Equation (2), the terrorist group is now aware of the security actions of both countries.

The state equation that describes the evolution over time of public safety in Europe, $S$, is the same as in Equation (3),

$$
\dot{S}=\gamma L+\alpha G-\beta A-\sigma S-\Psi
$$

The small country Hamiltonian is,

$$
H_{G}=\left[a_{1}\left(G-0.5 G^{2}\right)-a_{2} A+a_{3} L+a_{4} S\right]+\lambda_{1}[\gamma L+\alpha G-\beta A-\sigma S-\Psi]
$$

and the terrorists' Hamiltonian is,

$$
H_{A}=\left[b_{1}\left(A-0.5 A^{2}\right)-b_{2} S(G+L)\right]+\lambda_{2}[\gamma L+\alpha G-\beta A-\sigma S-\Psi]
$$

Maximizing the Hamiltonians with respect to the control variables yields,

$$
\begin{gathered}
\frac{\partial H_{G}}{\partial G}=0 \Rightarrow a_{1}(1-G)+\lambda_{1} \alpha=0 \Rightarrow G=1+\frac{\alpha \lambda_{1}}{a_{1}} \\
\frac{\partial H_{A}}{\partial A}=0 \Rightarrow A=1-\frac{\beta \lambda_{2}}{b_{1}}
\end{gathered}
$$

The adjoint equations are

$$
\dot{\lambda}_{1}-\delta \lambda_{1}=-\frac{\partial H_{G}}{\partial S} \Rightarrow \dot{\lambda}_{1}=(\delta+\sigma) \lambda_{1}-a_{4}
$$

and

$$
\dot{\lambda}_{2}-r \lambda_{2}=-\frac{\partial H_{A}}{\partial S} \Rightarrow \dot{\lambda}_{2}=(r+\sigma) \lambda_{2}+b_{2}(G+L)
$$

in which the usual transversality conditions apply. Differentiating (18) and (19) with respect to time and substituting into (20) and (21) yields the dynamic reaction functions of the small country and the terrorist organization,

$$
\dot{G}=(\delta+\sigma)(G-1)-\frac{\alpha a_{4}}{a_{1}}
$$

and

$$
\dot{A}=(r+\sigma)(A-1)-\frac{\beta b_{2}}{b_{1}}(G+L)
$$

As expected, (22) and (23) reflect how the small country's choice impacts that of the terrorist organization and vice versa. It is important to stress that, differently from Equations (8) and (9), these reaction functions now explicitly take into account the role of the large country security measures, $L$. 
The large country considers the dynamic reaction functions (22) and (23), as well as the state equation, in maximizing the objective function,

$$
\operatorname{Max}_{L} \int_{0}^{\infty}\left[\xi\left(L-0.5 L^{2}\right)-\varphi A+\rho_{1} S+\rho_{2} G\right] e^{-R t} d t
$$

subject to (17), (22) and (23). Note that the large country's objective function takes into account both the security measures of the small country and overall continental safety, reflecting full awareness.

The current-value Hamiltonian of the large country's problem is,

$$
\left.H_{L}=\left[\xi\left(L-0.5 L^{2}\right)-\varphi A+\rho_{1} S+\rho_{2} G\right]\right]+\lambda_{L}[\gamma L+\alpha G-\beta A-\sigma S-\Omega]+\mu_{1}\left[(\delta+\sigma)(G-1)-\frac{\alpha a_{4}}{a_{1}}\right]+\mu_{2}\left[(r+\sigma)(A-1)-\frac{\beta b_{2}(G+L)}{b_{1}}\right]
$$

where $\lambda$ and $\mu^{\prime}$ s are the large country's shadow prices of public safety and small country and terrorists' actions. The first-order conditions are,

$$
\begin{gathered}
\frac{\partial H_{L}}{\partial L}=0 \Rightarrow \xi(1-L)+\lambda_{L} \gamma-\frac{\beta b_{2}}{b_{1}} \mu_{2}=0 \Rightarrow L=1+\xi^{-1}\left[\lambda_{L} \gamma-\frac{\beta b_{2}}{b_{1}} \mu_{2}\right] \\
\dot{\lambda}_{L}-R \lambda_{L}=-\frac{\partial H_{L}}{\partial S} \Rightarrow \dot{\lambda}_{L}=(R+\sigma) \lambda_{L}-\rho_{1} \\
\dot{\mu}_{1}-R \mu_{1}=-\frac{\partial H_{L}}{\partial G} \Rightarrow \dot{\mu}_{1}=R \mu_{1}-\left\{\rho_{2}+\alpha \lambda_{L}+\mu_{1}(\delta+\sigma)-\mu_{2} \frac{\beta b_{2}}{b_{1}}\right\}
\end{gathered}
$$

and

$$
\dot{\mu}_{2}-R \mu_{2}=-\frac{\partial H_{L}}{\partial A} \Rightarrow \dot{\mu}_{2}=R \mu_{2}-\left\{-\varphi-\beta \lambda_{L}+\mu_{2}(r+\sigma)\right\}
$$

The steady state equilibrium value of the small country's security and large country's shadow price of continental public safety are easily found:

$$
\begin{gathered}
\dot{G}=0 \Rightarrow G^{*}=1+\frac{\alpha a_{4}}{a_{1}(\delta+\sigma)} \\
\dot{\lambda}_{L}=0 \Rightarrow \lambda_{L}^{*}=\frac{\rho_{1}}{(R+\sigma)}
\end{gathered}
$$

The steady state equilibrium values of the remaining variables are found by solving the following equations:

$$
\begin{gathered}
\dot{A}=0 \Rightarrow A=1+\frac{\beta b_{2}}{b_{1}(r+\sigma)}\left(G^{*}+L\right) \\
L=1+\xi^{-1}\left[\lambda_{L}^{*} \gamma-\frac{\beta b_{2}}{b_{1}} \mu_{2}\right]
\end{gathered}
$$

and

$$
\dot{\mu}_{2}=0 \Rightarrow \mu_{2}=\frac{\left[\varphi+\lambda_{L}^{*} \beta\right]}{[r+\sigma-R]}
$$

Substituting (25) into (27) yields the steady state value for the large country's shadow value of terrorist attacks:

$$
\mu_{2}^{*}=\frac{\left[\varphi(R+\sigma)+\rho_{1} \beta\right]}{[r+\sigma-R](R+\sigma)}
$$

Substituting (25) and (28) into (27) yields the steady state value of the large country's security:

$$
L^{*}=1+\xi^{-1}\left[\frac{\gamma \rho_{1}}{(R+\sigma)}-\frac{\beta b_{2}}{b_{1}} \frac{\left[\varphi(R+\sigma)+\rho_{1} \beta\right]}{[r+\sigma-R](R+\sigma)}\right]
$$


Substituting (24) and (29) into (26) yields the steady state value of the terrorist attacks:

$$
A^{*}=1+\frac{\beta b_{2}}{b_{1}(r+\sigma)}\left(G^{*}+L^{*}\right)
$$

Imposing $\dot{S}=0$ in Equation (17) and substituting (24), (29), and (30) yields the steady state value of continental public safety:

$$
S^{*}=\sigma^{-1}\left[\gamma L^{*}+\alpha G^{*}-\beta A^{*}-\Psi\right]
$$

Because we have different equilibriums between the myopic and full awareness scenarios, it is appropriate to conduct a stability analysis to determine which one is stable and, therefore, more likely to persist in the long term.

\section{Stability Analysis}

The canonical system of both the myopic and full awareness model is:

$$
\begin{gathered}
\dot{S}=\gamma L+\alpha G-\beta A-\sigma S-\Psi \\
\dot{G}=(\delta+\sigma)(G-1)-\frac{\alpha a_{4}}{a_{1}} \\
\dot{A}=(r+\sigma)(A-1)-\frac{\beta}{b_{1}}\left(b_{2} G+b_{3} L\right) \\
\dot{\lambda}_{L}=(R+\sigma) \lambda_{L}-\rho_{1} \\
\dot{\mu}_{1}=R \mu_{1}-\left\{\rho_{2}+\alpha \lambda_{L}+\mu_{1}(\delta+\sigma)-\mu_{2} \frac{\beta b_{2}}{b_{1}}\right\} \\
\dot{\mu}_{2}=R \mu_{2}-\left\{-\varphi-\beta \lambda_{L}+\mu_{2}(r+\sigma)\right\}
\end{gathered}
$$

We get the "Myopia Scenario" by setting $a_{3}=a_{4}=\rho_{1}=\rho_{2}=b_{3}=0$. In the full awareness scenario, we have $b_{2}=b_{3}>0$.

Substituting $L=1+\xi^{-1}\left[\lambda_{L} \gamma-\frac{\beta b_{2}}{b_{1}} \mu_{2}\right]$ in the canonical system, we derive the Jacobian calculated at the steady state:

$$
J=\left(\begin{array}{cccccc}
-\sigma & \alpha & -\beta & \gamma^{2} / \xi & 0 & \frac{\gamma \beta b_{2}}{\xi b_{1}} \\
0 & \delta+\sigma & 0 & 0 & 0 & 0 \\
0 & \frac{-\beta b_{2}}{b_{1}} & r+\sigma & \frac{-\gamma \beta b_{2}}{\xi b_{1}} & 0 & \frac{\left(\beta b_{2}\right)^{2}}{\xi b_{1}^{2}} \\
0 & 0 & 0 & R+\sigma & 0 & 0 \\
0 & 0 & 0 & -\alpha & R-\delta-\sigma & \frac{\beta b_{2}}{b_{1}} \\
0 & 0 & 0 & \beta & 0 & R-r-\sigma
\end{array}\right)
$$

Three eigenvalues can be easily derived and are given by:

$$
e_{1}=\delta+\sigma ; \quad e_{2}=R-\delta-\sigma ; \quad e_{3}=R+\sigma
$$

The remaining eigenvalues are eigenvalues of the $3 \times 3$-matrix (31) below:

$$
\left(\begin{array}{ccc}
-\sigma & -\beta & \frac{\gamma \beta b_{2}}{\xi b_{1}} \\
0 & r+\sigma & \frac{\left(\beta b_{2}\right)^{2}}{\xi b_{1}^{2}} \\
0 & 0 & R-r-\sigma
\end{array}\right)
$$


All eigenvalues are real and are given by the following:

$$
\left(\begin{array}{c}
\delta+\sigma \\
r+\sigma \\
R+\sigma \\
-\sigma \\
R-\delta-\sigma \\
R-r-\sigma
\end{array}\right)
$$

Result: For both, the case of myopia and full awareness, a saddle point stable equilibrium exists only if $R<\min (r+\sigma, \delta+\sigma)$.

The next section compares the myopic model with the full awareness model.

\section{Scenario Comparison: Myopia vs. Awareness}

In what follows, we compare the different scenarios that emerge from the model. It is easy to see that the full awareness model yields a greater value of security for the small country:

$$
G^{*}=1+\frac{\alpha a_{4}}{a_{1}(\delta+\sigma)}>1=\bar{G}
$$

In regards to the large country, there are two possibilities: (1) the large country is "extremely impatient", defined as $r+\sigma<R$, in which case the equilibrium is not stable, and (2) the large country is "relatively patient", defined as $r+\sigma>R$, in which case the equilibrium is stable (note, a sufficient condition for this outcome is that the large country is more patient than the small country, $R<r$ ).

In case (1) of an extremely impatient large country, the full awareness model yields a greater level of security investments for the large country (denoted $L_{1}^{*}$ ) than the myopic model:

$$
L_{1}^{*}=1+\xi^{-1}\left[\frac{\gamma \rho_{1}}{(R+\sigma)}-\frac{\beta b_{2}}{b_{1}} \frac{\left[\varphi(R+\sigma)+\rho_{1} \beta\right]}{[r+\sigma-R](R+\sigma)}\right]>1=\bar{L}
$$

In case (2) of a relatively patient large country, the full awareness model may yield a smaller level of security investments for the large country (denoted $L_{2}^{*}$ ) than the myopic model as long as $L_{2}^{*}>0$ and

$$
L_{2}^{*}=1+\xi^{-1}\left[\frac{\gamma \rho_{1}}{(R+\sigma)}-\frac{\beta b_{2}}{b_{1}} \frac{\left[\varphi(R+\sigma)+\rho_{1} \beta\right]}{[r+\sigma-R](R+\sigma)}\right]<1=\bar{L} \Leftrightarrow \frac{\gamma \rho_{1}}{(R+\sigma)}<\frac{\beta b_{2}}{b_{1}} \frac{\left[\varphi(R+\sigma)+\rho_{1} \beta\right]}{[r+\sigma-R](R+\sigma)}
$$

The above results are quite important for the magnitude of terrorist activities in both countries. We can see that the greatest level of terrorist activity will occur in the full awareness model with an extremely impatient large country. Since the model is explosive (because the equilibrium is unstable with an impatient large country), this is the worst case scenario.

At this point, a couple of remarks are necessary. Pruitt [39] (2006) suggests that negotiations with terrorists can be effective for moderate terror groups, not for apocalyptic terrorist groups (like $\mathrm{Al}$ Qaeda or ISIS). Bier and Hausken [40] (2011) explain terrorist backlash in terms of trust. If the terrorist violates trust, the government would presumably refrain from offering positive incentives such as negotiations, and instead, rely on negative incentives (brute force), but these may reduce the unit cost of terror attacks and backfire. One can even extend the issue from the perspective of a traditional Tullock contest framework (Faria et al. [41] (2014)), especially the literature on third-party intervention (e.g., Siqueira [42] (2003), Amegashie and Kutsoati [43] (2007), Chang, Potter, and Sanders [44] (2007), Chang and Sanders [45] (2009)). Since when the two countries increase their security level under "full awareness", the terrorist group should "invest" more in terrorism. For instance, Chang, Luo, and Zhang [46] (2018) show that the unsupported party (terrorists in our model) reacts with higher effort and has a winning probability over $50 \%$. 
When the large country is patient (case (2)), the level of terrorist activity is still greater than in the myopic model:

$$
A_{1}^{*}=1+\frac{\beta b_{2}}{b_{1}(r+\sigma)}\left(G^{*}+L_{1}^{*}\right)>A_{2}^{*}=1+\frac{\beta b_{2}}{b_{1}(r+\sigma)}\left(G^{*}+L_{2}^{*}\right)>\bar{A}=1+\frac{\beta b_{2}}{b_{1}(r+\sigma)}
$$

Therefore, the ranking of continental public safety is:

$$
S_{1}^{*}=\sigma^{-1}\left[\gamma L_{1}^{*}+\alpha G^{*}-\beta A_{1}^{*}-\Psi\right]<S_{2}^{*}=\sigma^{-1}\left[\gamma L_{2}^{*}+\alpha G^{*}-\beta A_{2}^{*}-\Psi\right]<\bar{S}=\sigma^{-1}[\gamma \bar{L}+\alpha-\beta \bar{A}-\Psi]
$$

If $\frac{\beta^{2} b_{2}}{b_{1}(r+\sigma)}>\gamma$, it is easy to see that $S_{1}{ }^{*}<S_{2}{ }^{*}$. However, to obtain $S_{2}{ }^{*}<\bar{S}$, it is necessary to assume that the difference $\frac{\alpha^{2} a_{4}}{a_{1}(\delta+\sigma)}$ is small enough so as to guarantee the inequality stands.

The above ranking results show that the full awareness model yields larger investments in security and more terrorist attacks than the myopic model. The scenario of an impatient large country is the one with more investments in safety and, also, more terrorist attacks. However, it is unstable and explosive. Surprisingly, continental safety is higher in the myopic model than in the full awareness model.

\section{Discussion}

In this section, with the advantage of hindsight, we can relate what happened in Europe during the Islamic terrorist campaign immediately after the onset of the Open Door Policy. Terrorist attacks hitting France and Belgium can be seen as an example of the full awareness model with a large impatient country, France, and a small country, Belgium, that have a long history of collaboration in anti-terror, with both being very aware of imminent terrorist attacks. Even so, they were hit harder with over 200 deaths in France and over 30 in Belgium from November of 2015 to 2016. For the sake of comparison, Germany and Turkey during the same period provide an example of the full awareness scenario, with Germany as a large but relatively patient country realizing 12 deaths and Turkey as a small country realizing 62 deaths. Finally, Germany and Poland can be seen as an example of myopia between a large (Germany) and a small (Poland) country, since, in spite of German leadership in the open borders initiative, Poland decided not to collaborate, avoiding receiving immigrants from Syria. Curiously, in 2017, according to Politico: "Poland issued more visas to foreign workers than any other country in Europe. Eighty-five percent of them went to people from Ukraine-a predominantly white, Christian country-looking for work." ${ }^{\prime 6}$ In the period examined, Poland had zero attacks and casualties. These observations show the relevance of our model, since it confirms the inequalities in equation (32).

\section{Concluding Remarks}

This paper analyzed a hierarchical differential game, with a large and a small country and a terrorist organization, as a model of the actual European refugee situation. Terrorists may enter Europe as refugees, taking advantage of the Open Door Policy, to attack both countries.

Two scenarios were considered: myopia and full awareness. Countries are myopic when they ignore each other's security efforts, and the terrorist group is myopic when it only considers the weakest link's security effort. In the full awareness model, countries know that their expenditure on safety has a positive externality on the safety of their neighbors and on the whole continent.

A comparison between the scenarios shows that for an extremely impatient large country, full awareness yields a greater level of security effort for the large country, a greater level of security effort for the small country, and, because of backlash, more terrorist attacks. Stability analysis, however, shows that this equilibrium is unstable.

6 See https://www.politico.eu/article/poland-two-faced-immigration-strategy-ukraine-migrants. 
The full awareness model with a patient large country is stable and lies in between the full awareness model with an impatient large country and the myopic model. Although it yields larger investments in security, this comes at a price of more terrorist attacks than the myopic model. As a consequence, continental safety is higher in the myopic model. Consequently, while myopia would typically be viewed as a naïve position, which would open up a decision maker to being taken advantage of, we see that in this context it may actually prove to be beneficial.

The application of differential games to analyze situations of terrorism and conflict is still quite limited. Broadly, we view such applications to be a fruitful area for future research. More specifically, the present work could be extended by considering slightly different objective functions for the players or by allowing for a wider array of strategic decisions to be made over time.

Author Contributions: Conceptualization, J.R.F. and A.N.; methodology, J.R.F. and A.N.; formal analysis, J.R.F., A.N., A.B., and T.M.; investigation, J.R.F., A.N., A.B., and T.M.; writing-original draft preparation, J.R.F. and A.N.; writing-review and editing, J.R.F., A.N., A.B., and T.M. All authors have read and agreed to the published version of the manuscript.

Funding: This research received no external funding.

Conflicts of Interest: The authors declare no conflict of interest.

\section{References}

1. Hausken, K. Probabilistic risk analysis and game theory. Risk Anal. 2002, 22, 17-27. [CrossRef] [PubMed]

2. Hausken, K. Income, interdependence, and substitution effects affecting incentives for security investment. J. Account. Public Policy 2006, 25, 629-665. [CrossRef]

3. Bier, V.; Oliveros, S.; Samuelson, L. Choosing what to protect: Strategic defensive allocation against an unknown attacker. J. Public Econ. Theory 2007, 9, 563-587. [CrossRef]

4. Mathews, T.; Lowenber, A. The interdependence between homeland security efforts of a state and a terrorist's choice of attack. Confl. Manag. Peace Sci. 2012, 29, 195-218. [CrossRef]

5. Faria, J.R.; Arce, D. Terror support and recruitment. Def. Peace Econ. 2005, 16, 263-273. [CrossRef]

6. Faria, J.R.; Arce, D. Counterterrorism and its impact on terror support and recruitment: Accounting for backlash. Def. Peace Econ. 2012, 23, 431-445. [CrossRef]

7. Siqueira, K.; Sandler, T. Terrorist backlash, terrorism mitigation, and policy delegation. J. Public Econ. 2007, 95, 1800-1815. [CrossRef]

8. Lischer, S. Dangerous Sanctuaries: Refugee Camps, Civil War, and the Dilemmas of Humanitarian Aid; Cornell University Press: Ithaca, NY, USA, 2005.

9. Salehyan, I.; Gleditsch, K.S. Refugees and the spread of civil war. Int. Organ. 2006, 60, 335-366. [CrossRef]

10. Buhaug, H.; Gleditsch, K.S. Contagion or confusion? Why conflicts cluster in space. Int. Stud. Q. 2008, 52, 215-233. [CrossRef]

11. Salehyan, I. The externalities of civil strife: Refugees as a source of international conflict. Am. J. Political Sci. 2008, 52, 787-801. [CrossRef]

12. Salehyan, I. Rebels without Borders: Transnational Insurgencies in World Politics; Cornell University Press: Ithaca, NY, USA, 2009.

13. Piazza, J.A. Incubators of terror: Do failed states and failing states promote transnational terrorism? Int. Stud. Q. 2008, 52, 469-488. [CrossRef]

14. Barros, C.P.; Proença, I.; Faria, J.R.; Gil-Alana, L. Are USA citizens at risk of terrorism in Europe? Def. Peace Econ. 2007, 18, 495-507. [CrossRef]

15. Barros, C.P.; Faria, J.R.; Gil-Alana, L. Terrorism in Africa: Persistence and poverty. J. Policy Model. 2008, 30, 55-69. [CrossRef]

16. Murdoch, J.; Sandler, T. Civil wars and economic growth: Spatial dispersion. Am. J. Political Sci. 2004, 48, 138-151. [CrossRef]

17. Collier, P.; Hoeffler, A. Greed and grievance in civil war. Oxf. Econ. Pap. 2004, 56, 563-595. [CrossRef]

18. Lowenberg, A.D.; Mathews, T. Why Iraq? Def. Peace Econ. 2008, 19, 1-20. [CrossRef]

19. Choi, S.-W.; Salehyan, I. No Good Deed Goes Unpunished: Refugees, Humanitarian Aid, and Terrorism. Confl. Manag. Peace Sci. 2013, 30, 53-75. [CrossRef] 
20. Bueno de Mesquita, E. The political economy of terrorism: A selective overview of recent work. Political Econ. 2008, 10, 1-12.

21. Intrilligator, M.D. The economics of terrorism. Econ. Inq. 2010, 48, 1-13. [CrossRef]

22. Feichtinger, G.; Hartl, R.F.; Kort, P.M.; Novak, A.J. Terrorism control in the tourism industry. J. Optim. Theory Appl. 2001, 108, 283-296. [CrossRef]

23. Udwadia, F.; Leitmann, G.; Lambertini, L. A dynamical model of terrorism. Discret. Dyn. Nat. Soc. 2006. [CrossRef]

24. Caulkins, J.P.; Grass, D.; Feichtinger, G.; Tragler, G. Optimizing counter-terror operations: Should one fight fire with "fire" or "water"? Comput. Oper. Res. 2008, 35, 1874-1885. [CrossRef]

25. Jensen, T. Optimal counterterrorism and the recruitment effect of Large terrorist attacks: A simple dynamic model. J. Theor. Politics 2011, 23, 69-86. [CrossRef]

26. Faria, J.R.; Arce, D. A vintage model of terrorist organizations. J. Conflict Resolut. 2012, 56, 629-650. [CrossRef]

27. Faria, J.R. An integro-differential approach to terrorism dynamics. Def. Peace Econ. 2011, 22, 595-605. [CrossRef]

28. Kaplan, E.H. Terror queues. Oper. Res. 2010, 58, 773-784. [CrossRef]

29. Jensen, T. The timing of terrorist attacks: An optimal stopping approach. Res. Politics 2016, 3. [CrossRef]

30. Faria, J.R. Terror cycles. Stud. Nonlinear Dyn. Econom. 2003, 7, 1-9. [CrossRef]

31. Feichtinger, G.; Novak, A.J. Terror and counterterror operations: Differential game with cyclical Nash solution. J. Optim. Theory Appl. 2008, 139, 541-556. [CrossRef]

32. Novak, A.J.; Feichtinger, G.; Leitmann, G. A Differential game related to terrorism: Nash and Stackelberg strategies. J. Optim. Theory Appl. 2010, 144, 533-555. [CrossRef]

33. Doris, A.; Behrens, D.; Caulkins, J.; Feichtinger, G.; Tragler, G. Incentive stackelberg strategies for a dynamic game on terrorism. In Advances in Dynamic Game Theory; Jørgensen, S., Quincampoix, M., Vincent, T.L., Eds.; Birkhäuser: Boston, MA, USA, 2017; pp. 459-486.

34. Wang, Z.; Yin, Y.; An, B. Computing optimal monitoring strategy for detecting terrorist plots. In Proceedings of the Thirtieth AAAI Conference on Artificial Intelligence (AAAI'16), Phoenix, AZ, USA, 21 February 2016; pp. 637-643.

35. Short, M.; McCalla, S.; D'Orsogna, M. Modelling radicalization: How small violent fringe sects develop into large indoctrinated societies. R. Soc. Open Sci. 2017. [CrossRef] [PubMed]

36. Gaibulloev, K.; Sandler, T. What we have learned about terrorism since 9/11. J. Econ. Lit. 2019, 57, $275-328$. [CrossRef]

37. Enders, W.; Sandler, T. The Political Economy of Terrorism, 2nd ed.; Cambridge University Press: Cambridge, UK, 2012.

38. Hausken, K. Choosing what to protect when attacker resources and asset valuations are uncertain. Oper. Res. Decis. 2014, 3. [CrossRef]

39. Pruitt, D.G. Negotiation with terrorists. Int. Negot. 2006, 11, 371-394. [CrossRef]

40. Vicki, M.; Bier, V.M.; Hausken, K. Endogenizing the sticks and carrots: Modeling possible perverse effects of counterterrorism measures. Ann. Oper. Res. 2011, 186, 39-59.

41. Faria, J.; Mixon, F.; Caudill, S.; Wineke, S. Two-dimensional effort in patent-race and rent-seeking contests: The case of telephony. Games 2014, 5, 116-126. [CrossRef]

42. Siqueira, K. Conflict and Third-party Intervention. Def. Peace Econ. 2003, 14, 389-400. [CrossRef]

43. Amegashie, J.A.; Kutsoati, E. (Non)Intervention in Intra-state Conflicts. Eur. J. Political Econ. 2007, 23, 754-767. [CrossRef]

44. Chang, Y.-M.; Potter, J.; Sanders, S. War and Peace: Third-party Intervention in Conflict. Eur. J. Political Econ. 2007, 23, 954-974. [CrossRef]

45. Chang, Y.-M.; Sanders, S. Raising the Cost of Rebellion: The Role of Third-party Intervention in Intra-state Conflict. Def. Peace Econ. 2009, 20, 149-169. [CrossRef]

46. Chang, Y.-M.; Luo, Z.; Zhang, Y. The timing of third-party intervention in social conflict. Def. Peace Econ. 2018, 29, 91-110. [CrossRef]

(C) 2020 by the authors. Licensee MDPI, Basel, Switzerland. This article is an open access article distributed under the terms and conditions of the Creative Commons Attribution (CC BY) license (http://creativecommons.org/licenses/by/4.0/). 